\title{
Does the natural "microcosm" created by Tuber aestivum affect soil microarthropods? A new hypothesis based on Collembola in truffle culture
}

\author{
Cristina Menta ，Luis Gonzaga García-Montero , Stefania Pinto , \\ Federica Delia Conti , Giampietro Baroni , Mattia Maresi
}

\begin{abstract}
A B S T R A C T
The interactions between fungi and soil fauna are not well known. Some studies suggest that soil microarthropods play an important role in fungi dispersion, but little is still known about the interaction between truffle and soil microarthropods. The aim of this study was to investigate the ability of the truffle Tuber aestivum to modify soil biogeochemistry (i.e. create a zone of scarce vegetation around the host plant, called a burn or brûlê) and to highlight the effects of the brûlé on the soil fauna community. We compared soil microarthropod communities found in the soil inside versus outside the T. aestivum brûlé with the chemistry of soil collected inside versus outside the brûlé. The study was carried out in three Mediterranean areas, two in Italy and one in Spain. The results confirmed the ability of T. aestivum to modify soil biogeochemistry in the brûlê: $\mathrm{pH}$ was higher and total organic carbon tended to be lower inside the brûle compared to outside. Soil fauna communities showed some interesting differences. Some groups, such as Symphyla and Pauropoda, adapted well to the soil; some Collembolan families, and biodiversity and soil quality indices were generally higher outside the brûlé. Folsomia sp. showed higher abundance in the soil of the brûlé compared to outside. The results suggest that some Collembola groups may be attracted by the fungal metabolites produced by T. aestivum, while other Collembola and other microarthropods may find an unfavourable environment in the soil of the brûle. The next steps will be to confirm this hypothesis and to extend the study to other keys groups such as nematodes and earthworms and to link fluctuations of soil communities with the biological phases of truffle growth.
\end{abstract}

\section{Introduction}

Fungi are widespread within the soil and represent a considerable potential food resource for soil fauna such as nematodes, springtails, earthworms, flies and beetles, many of which graze on fungal mycelia and can substantially alter fungal morphology and physiology (Anderson, 2001; Harold et al., 2005; Pacioni et al., 1991; Rotheray et al., 2011). The interaction between soil microarthropods and fungi deserves special attention because both groups represent major trophic and functional groups in the soil food web (Böllmann et al., 2010).

Soil fauna could have a positive or negative effect on fungal growth, dispersion and fruit body production. Such effects are likely to alter fungal fitness, and therefore their combativeness in interaction with other soil microorganisms, including fungi (Rotheray et al., 2011). Various authors have described some mechanisms explaining the impact of soil microarthropods on fungal communities. For instance, Hanlon and Anderson (1979) indicated that microarthropod feeding activities can exert a strong differential effect on fungal and bacterial populations, and some reviews on arbuscular mycorrhizae and soil fauna interactions suggest that Collembola have the potential to restrict mycorrhizal functioning in the field (Fitter and Garbaye, 1994; Fitter and Sanders, 1992).

It is less known, however, that certain communities of ectomycorrhizal (ECM) fungi can alter forest soil biogeochemistry, which could cause changes in microarthropod communities. Two important examples appear to be the truffle (Tuber Micheli ex Wiggers) brûlés and the dense hyphal mats formed by ectomycorrhizal (ECM) fungi.

Various ECM fungal species have been found to form dense aggregations of hyphae, known as mats, which are prominent 
features in Douglas-fir forest ecosystems. These soils, densely colonized by the ECM fungi, create a soil environment with different microbial activities when compared to non-mat forest soils. Cromack et al. (1988) showed increased TOC (total organic carbon) and $\mathrm{N}$ values in ECM-mat soils compared to non-mat soils. Kluber et al. (2010) indicate that ECM-mat soils show greater microbial biomass $C$ (in mineral horizon) and enzyme profile differences (greater chitinase, phosphatase and phenoloxidase activity) compared to non-mat soils, and from 2.7 to 40 times more oxalate and lower pH than non-mat soils. Cromack et al. (1988) studied the interactions between soil fauna and some ECM mats and demonstrated that mites and springtails (and others, such as nematodes) are more abundant within ECM-mat-colonized soil compared to non-mat forest soils. These authors concluded that soil invertebrates, such as microarthropods, could utilize fungalECM-mat resources on an opportunistic basis, which could explain the observed dynamics of microarthropod communities in ECMmat soils.

Trees infected with the ECM fungi sometimes have an area around the trunk where the growth of other plants is inhibited either permanently or for part of the year. Some ECM fungi that produce these clearings, or brûlés (burns), are Tuber aestivum Vittad. (summer truffle), Tuber melanosporum Vittad. (black truffle) and Scleroderma Pers. The Tuber mycelium produces multiple substances that adversely affect young trees and seed germination, and fungal infection in the roots of weeds results in severe necrosis in the root cortices (Plattner and Hall, 1995). Tuber mycorrhizal activity, mycelium growth and carpophore production take place inside the brûlé, mainly behind the brûlé line (Callot, 1999). Some authors have explained the production and development of brûlés (Granetti et al., 2005; Sourzat, 2004) but others have indicated that the ecological conditions relating to brûlés are yet to be clarified (Callot et al., 1999; García-Montero et al., 2009, 2014a,b; Ricard, 2003). There is virtually no reference to the possible effects of Tuber species on soil fauna.

As with ECM mats, Garcia-Montero et al. (2009) indicated that Tuber brûlés can also alter soil biogeochemistry and some authors described how T. melanosprum brûlés decrease TOC in internal soils in relation to external soils (Callot, 1999; García-Montero et al., 2014a; Granetti et al., 2005; Ricard, 2003). In calcareous Mediterranean areas, García-Montero et al. (2014b) indicated that T. aestivum significantly increases soil $\mathrm{pH}$ and significantly decreases total carbonate in the internal soils of brûlés compared to external soils. Moreover, in Mediterranean climates where Tuber spp. thrives, Mello et al. (2013) indicated that the lack of vegetation that occurs in their brûlés could cause significant changes in light exposure and soil moisture level, leading in turn to water stress in the brûlé soil, especially in the summer months.

On the basis of these considerations, the aims of this study were: (1) to increase knowledge of the ability of Tuber aestivum brûlés to modify soil biogeochemistry; (2) to characterize soil microarthropod communities in soils affected by the presence of $T$. aestivum brûlés. We therefore compared the soil found inside a $T$. aestivum brûle with that observed outside the brûlé (control) in terms of physical and chemical characteristics, biodiversity and abundance of soil microarthropods.

With regard to the latter indicator, we hypothesize that some groups may be affected negatively by the almost total absence of vegetation in the brûlé, while others, especially fungivorous Collembola taxa, may find better conditions in the brûlé in terms of habitat and/or trophic source. We conducted the study in three different areas, one in Spain and two in Italy, to verify if the trend of soil chemistry and soil fauna would be confirmed in different areas. We assumed that the two conditions, inside and outside the brûlé, were characterized by the same climate, annual rainfall and tree presence, but had different grass and plant cover due to the direct action of the $T$. aestivum mycelium.

\section{Materials and methods}

\subsection{Study areas}

The study was carried out in three Mediterranean areas, two in Italy and one in Spain. Table 1 summarises the environmental characteristics of the study areas. The municipalities and exact geographic coordinates of the studied brûlés were not revealed, in order to maintain the secrecy of the Tuber brûlé locations. A total of nine brûlés characterized by the presence of $T$. aestivum were identified in each area. Soil samples were collected during $T$. aestivum fructification, June in Italy and May in Spain.

\subsection{Soil analysis}

The samples for soil analysis were taken according to FAO recommendations (FAO, 1990) from inside the holes made by the collectors to extract the carpophores in brûlés with a significant production. Only the first $30 \mathrm{~cm}$ of each soil profile was studied because most Tuber form mycorrhizas and bear fruit in this range (Verlhac et al., 1990). We collected 9 soil samples inside and 9 outside each brûlé for chemical analyses. The following soil

Table 1

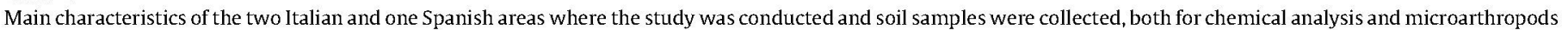
characterization, to characterize Tuber aestivum brûlé, and soil sampling period.

\begin{tabular}{|c|c|c|c|}
\hline & Area I & Area II & Area III \\
\hline Country & Italy & Italy & Spain \\
\hline Province & Teramo & Piacenza & Guadalajara \\
\hline Altitude & $630 \mathrm{~m}$ a.s.l. & $721 \mathrm{~m}$ a.s.l. & $1000 \mathrm{~m}$ a.s.l. \\
\hline $\begin{array}{l}\text { Average annual } \\
\text { rainfall }\end{array}$ & $937 \mathrm{~mm}$ & $810 \mathrm{~mm}$ & $797 \mathrm{~mm}$ \\
\hline $\begin{array}{l}\text { Medium } \\
\text { temperature }\left({ }^{\circ} \mathrm{C}\right)\end{array}$ & 14.9 & 10.6 & 9.7 \\
\hline $\begin{array}{l}\text { Geological } \\
\text { substratum }\end{array}$ & $\begin{array}{l}\text { Cover detritus-eluvial of the } \\
\text { Holocene origin }\end{array}$ & $\begin{array}{l}\text { Lutetian limestones and marly limestones alternating marls and } \\
\text { calcareous marls }\end{array}$ & $\begin{array}{l}\text { Jurassic and Cretaceous limestone and } \\
\text { dolomites }\end{array}$ \\
\hline Soil & Mollisoil $^{\mathrm{a}}$ & Calcaric cambisol $^{\mathrm{b}}$ & Lithic and rendzic leptosols $s^{c}$ \\
\hline Plant & Quercus pubescens & Quercus pubescens & Quercus faginea \\
\hline Soil sampling period & Spring 2012 & Spring 2013 & Spring 2012 \\
\hline
\end{tabular}

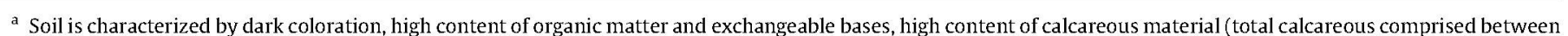
9.6 and $14.3 \%$, active calcareous between 2 and 14\%), pH comprised between 7.2 and 8.3 (detected in $\mathrm{H}_{2} \mathrm{O}$ ) and high content of superficial stones.

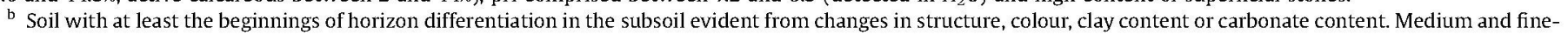
textured. Materials derived from a wide range of rocks.

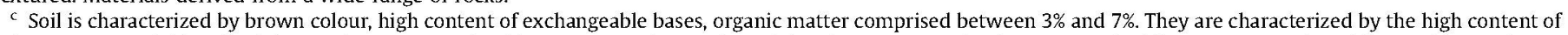
calcareous material (total calcium carbonate comprised between 7 and $8 \%$, active calcium between 3 and $7 \%$ ), pH comprised between 7.2 and 8.3 (detected in $\mathrm{H}_{2} \mathrm{O}$ ). 
analyses were conducted: pH (in water), using the ISRIC (1995) method; total organic carbon (TOC) in the Spanish samples, using the ISRIC (1995) method; TOC in the Italian samples, using Ball's method (Ball, 1964) (using loss of weight on ignition and the Van Bemmelen conversion factor); and moisture content (\%), using the gravimetric method.

\subsection{Soil microarthropod extraction}

Soil samples were taken inside each brûlé (more or less centrally) and outside it (at least $5 \mathrm{~m}$ from the brûlé edge). A total of 54 soil samples were collected ( 18 in each area, 9 inside the brûlé and 9 outside). Each soil sample measured $100 \mathrm{~cm}^{2}$ and was taken at a depth of $10 \mathrm{~cm}$. Microarthropods were extracted using a Berlese-Tüllgren funnel. The specimens were placed in a preserving solution ( $75 \%$ ethyl alcohol and $25 \%$ glycerol by volume) and identified to different taxonomic levels (class for Myriapoda, order for Hexapoda, Chelicerata and Crustacea, and family for Collembola). The organisms belonging to each taxon were counted in order to estimate their density at the sampling depth $(10 \mathrm{~cm})$, extrapolating the number of individuals to $1 \mathrm{~m}^{2}$ (ind $/ \mathrm{m}^{2}$ ).

\subsection{Soil biodiversity indices}

The biodiversity of soil animal communities was evaluated using the number of observed taxa (NT), the Shannon diversity index $\left(\mathrm{H}^{\prime}\right)$ and Pielou's evenness index $(\mathrm{J})$. The latter two indices were calculated using the number of specimens observed in each sample for each taxonomic level.

Soil biological quality was estimated by applying the Acari-toCollembola ratio (A/C, Bachelier, 1986), the QBS-ar index (Parisi et al., 2005) and the QBS-c index (Parisi and Menta, 2008). The A/C index represents the biodynamic conditions of the soil. Under good stable conditions, the percentage of mites is higher than that of springtails, while it tends to decrease in favour of springtails in degraded situations. The QBS-ar index was developed in order to combine two important aspects regarding soil microarthropods: (1) their presence in the soil, intended as biodiversity; (2) the level of microarthropod adaptation to the soil, intended as vulnerability. This index is based on the idea that a high number of microarthropod groups (biodiversity) well adapted to soil habitats (vulnerable to soil perturbation) indicates a good soil biological quality. The QBS-ar index is applied to the soil microarthropod community, divided in accordance with the biological form approach (sensu Sacchi and Testard, 1971) in order to: (1) evaluate the microarthropods' level of adaptation to life in the soil environment (Parisi, 1974), and (2) overcome the well-known difficulties of taxonomic analysis to species level for soil mesofauna. Edaphic microarthropods are known to display morphological characteristics that give evidence of adaptation to soil environments, such as reduction or loss of pigmentation and visual apparatus, streamlined body form, with reduced and more compact appendages (hairs, antennae and legs), reduction or loss of flying, jumping or running adaptations and a reduced waterretention capacity, e.g. thinner cuticle and a lack of hydrophobic compounds on the outer surface (Parisi, 1974). By focusing on the presence of these characteristics, and not requiring complex taxonomic identification to the species level, QBS-ar analysis can also be used by non-specialists. The main phases for obtaining the QBS-ar values are: (1) soil sampling; (2) microarthropod extraction; (3) preservation of the collected specimens; (4) determination of biological forms and assignment of the ecologicalmorphological index (EMI); and (5) calculation of the QBS-ar index as the sum of the EMI values (Parisi et al., 2005). The EMI is a value assigned at each taxonomic group and ranges from 1 to 20 , from the lowest to the greatest adaptation to the soil. For more details see Gardi et al. (2008); Tabaglio et al. (2009); Menta et al. (2011); Blasi et al. (2013) and Menta et al. (2014).

Because of the important role played by springtails in the litter turnover, an index based exclusively on the Collembola community was applied. This index, named QBS-c, is calculated using the biological form approach (Parisi and Menta, 2008). Like the QBS-ar, the QBS-c is based on the principle of the greater vulnerability of organisms that are well adapted to the soil conditions. After soil extraction, Collembola were separated and classified at a family level. For each family, the biological forms with different EMI values (ranging in relation to the level of adaptation to the soil, from $0=$ no adaptation to $40=$ maximum adaptation) were recorded. The sum of all the EMI values associated with the biological forms identified in the samples gives the QBS-c value (Parisi and Menta, 2008). Organisms belonging to the Folsomia (Isotomidae) genus were classified separately because they displayed a different trend compared to their family.

\subsection{Statistical analysis}

The Wilcoxon test was conducted to highlight differences in physical and chemical parameters between inside and outside the brûlé.

To characterize soil fauna community in the three areas, comparisons of both densities of organisms and indices were carried out. Taxon densities were transformed into $\sqrt{ }(X+0.5)$ to avoid the problem of zeroes. The two-way ANOVA were applied, (area vs. burn) to highlight differences among the density groups; the influence of the study area and the position inside or outside the brûle was investigated. Tukey's pairwise for the comparison of significant values ( $p$-value $<0.05$ ) was carried out for post-hoc analysis. Index data were analysed untransformed and compared using the Wilcoxon test for paired samples to highlight differences between soil fauna inside and outside the brûlé. The same test was applied to highlight differences in the Collembola densities inside and outside the brûlé. All the statistical analyses were performed using R 3.0.1 statistical software (R Development Core Team, 2013).

\section{Results}

\subsection{Soil characterisation}

Table 2 shows the physical and chemical properties of the soil samples collected inside and outside the T. aestivum brûlés. Many of the soil samples had a moderately alkaline $\mathrm{pH}$. Levels of TOC were moderate.

The results of the Wilcoxon test indicated that TOC, organic matter and $\mathrm{pH}$ differed significantly according to the location of the soil, namely whether it was inside or outside the brûlés. Organic matter and TOC content were significantly lower (considering $p<0.1$ ) in the soils collected inside the brûlés, in areas I and III. In area II the difference between the two environments was not significant. $\mathrm{pH}$ was significantly higher inside compared to external soils in the three areas, while water content was higher outside in area III.

\subsection{Microarthropod community}

A total of 9329 specimens belonging to 19 taxonomic groups of soil microarthropods (distributed between Chelicerata, Crustacea, Myriapoda and Hexapoda) were identified from the 54 soil samples collected. Table 3 shows the taxa found and the average and standard errors of taxa abundances (expressed as ind $/ \mathrm{m}^{2}$ ) for the three areas. When considering the entire soil microarthropod community, Acari and Collembola were the most abundant groups. Coleoptera, Diptera and Hymenoptera, all adults, showed 
Table 2

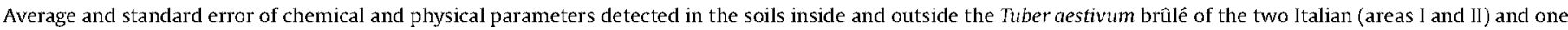
Spanish (area III) areas studied; $p$-value: statistical significance of the differences between inside and outside of the brûlé.

\begin{tabular}{|c|c|c|c|c|c|c|c|c|c|}
\hline & \multicolumn{3}{|l|}{ Area I } & \multicolumn{3}{|l|}{ Area II } & \multicolumn{3}{|l|}{ Area III } \\
\hline & Inside & Outside & $p$-value & Inside & Outside & $p$-value & Inside & Outside & $p$-value \\
\hline $\mathrm{pH}$ & $7.82 \pm 0.03$ & $7.6 \pm 0.05$ & ${ }^{* * *}$ & $8.14 \pm 0.03$ & $7.97 \pm 0.03$ & $* * *$ & $7.85 \pm 0.06$ & $7.58 \pm 0.05$ & ${ }^{*}$ \\
\hline Moisture (\%) & $8.28 \pm 1.38$ & $9.65 \pm 1.78$ & - & $8.10 \pm 0.73$ & $8.73 \pm 1.21$ & - & $17.60 \pm 1.06$ & $20.16 \pm 1.19$ & $* *$ \\
\hline Organic matter (\%) & $9.60 \pm 0.43$ & $12.10 \pm 1.30$ & 0.065 & $5.04 \pm 0.50$ & $5.73 \pm 0.40$ & - & $5.70 \pm 0.70$ & $7.14 \pm 0.88$ & 0.055 \\
\hline Organic carbon (\%) & $5.58 \pm 0.25$ & $7.03 \pm 0.75$ & 0.065 & $2.93 \pm 0.29$ & $3.33 \pm 0.23$ & - & $3.31 \pm 0.41$ & $4.51 \pm 0.51$ & 0.055 \\
\hline
\end{tabular}

${ }^{*} p<0.05$.

$p<0.01$.

$p<0.001$.

abundance, in some cases even higher than $1000 \mathrm{ind} / \mathrm{m}^{2}$. Pauropoda, Symphyla, Protura, Chilopoda, Hemiptera, Coleoptera and Diptera, the last two larvae, showed lower abundances. Pseudoscorpiones, Araneae, Isopoda, Diplopoda and Diplura were absent in several soil samples. Mycrocoryphia and Psocoptera were only sporadically present.

The two-way ANOVA showed significant differences between the three study areas for Pseudoscorpiones ( $p$ : 0.036), Acari ( $p$ : 0.033 ), Pauropoda ( $p: 0.006)$, Symphyla ( $p: 0.059)$, Chilopoda ( $p$ : $0.004)$, Protura $\left(p: 4.7 \times 10^{-8}\right)$, Collembola $(p: 0.0002)$ and Coleoptera larvae ( $p: 0.036)$, and between inside and outside the brûlé for Acari ( $p$ : 0.040$)$, Pauropoda ( $p$ : 0.077), Symphyla ( $p$ : $0.021)$ and Hemiptera ( $p: 0.028)$. These differences were investigated using Tukey's test, the results of which are set out below.

\subsubsection{Area $I$}

In this area we found lower densities of microarthropods inside compared to outside the brûlés $\left(12,429\right.$ ind $/ \mathrm{m}^{2}$ inside and $25,861 \mathrm{ind} / \mathrm{m}^{2}$ outside), and 15 taxonomic groups inside and 17 outside. The difference between the numbers of groups (NT) found inside and outside was statistically significant (Table 4). Symphyla and Hemiptera abundances were significantly lower inside the brûlés compared to outside (Table 3 ). The other microarthropod groups showed no significant trends, although in some cases (Coleoptera adults, Hymenoptera, and Lepidoptera larvae) abundances were higher inside the $T$. aestivum brûlés compared to outside. On the other hand, the abundances were on average higher outside for the other groups, but the numbers of specimens belonging to these groups were too low, and the dispersion of the data was too high, to highlight any significant differences.

An analysis of the Collembolan community showed significant differences between the densities of these organisms found outside and inside the burns (Table 5). Isotomidae was the most widely represented family, both inside and outside the burns, followed by the Hypogastruridae community collected outside the burns and the Tullbergidae family. The Wilcoxon test for paired samples highlights some significant differences for the Hypogastruridae, Isotomidae, Sminthurididae families, which show higher

Table 3

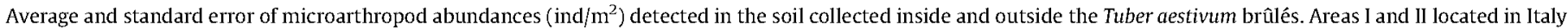
and area III in Spain; $p$-value: differences between inside and outside of the brûles.

\begin{tabular}{|c|c|c|c|c|c|c|c|c|c|c|}
\hline \multirow[b]{2}{*}{ Taxa } & & \multicolumn{3}{|l|}{ Area I } & \multicolumn{3}{|l|}{ Area II } & \multicolumn{3}{|l|}{ Area III } \\
\hline & & Inside & Outside & $\overline{p \text {-value }}$ & Inside & Outside & $\overline{p \text {-value }}$ & Inside & Outside & $\overline{p \text {-value }}$ \\
\hline Pseudoscorpiones & & $7 \pm 7$ & $38 \pm 19$ & - & - & $7 \pm 7$ & - & - & - & - \\
\hline Araneida & & $19 \pm 19$ & $64 \pm 50$ & - & $14 \pm 9$ & $57 \pm 42$ & - & - & - & - \\
\hline Acari & & $4223 \pm 804$ & $7892 \pm 1892$ & - & $2194 \pm 412$ & $3602 \pm 610$ & - & $5364 \pm 949$ & $5895 \pm 1246$ & - \\
\hline Isopoda & & $19 \pm 10$ & $25 \pm 14$ & - & - & - & - & - & - & - \\
\hline Diplopoda & & $7 \pm 7$ & $108 \pm 50$ & - & $7 \pm 7$ & $50 \pm 35$ & - & - & - & - \\
\hline Pauropoda & & - & $7 \pm 7$ & - & $21 \pm 21$ & $106 \pm 38$ & $* \star *$ & $50 \pm 30$ & $35 \pm 15$ & - \\
\hline Symphyla & & $96 \pm 33$ & $516 \pm 168$ & $*$ & $50 \pm 30$ & $114 \pm 54$ & - & $120 \pm 78$ & $191 \pm 69$ & - \\
\hline Chilopoda & & $76 \pm 34$ & $172 \pm 46$ & - & $21 \pm 15$ & $14 \pm 9$ & - & $28 \pm 11$ & $42 \pm 18$ & - \\
\hline Protura & & - & $25 \pm 17$ & - & $219 \pm 83$ & $531 \pm 214$ & - & $28 \pm 28$ & $7 \pm 7$ & - \\
\hline Diplura & & $25 \pm 14$ & $83 \pm 29$ & - & - & $50 \pm 26$ & - & $28 \pm 15$ & $21 \pm 15$ & - \\
\hline Collembola & & $5285 \pm 2169$ & $13210 \pm 7015$ & - & $4465 \pm 1434$ & $2272 \pm 524$ & - & $709 \pm 194$ & $814 \pm 230$ & - \\
\hline Microcoryphia & & - & - & - & - & - & - & $14 \pm 14$ & - & - \\
\hline Dermaptera & & - & - & - & - & - & - & - & - & - \\
\hline Orthoptera & & - & - & - & - & - & - & - & - & - \\
\hline Psocoptera & & - & - & - & $35 \pm 22$ & $78 \pm 35$ & - & - & - & - \\
\hline Hemiptera & & $7 \pm 7$ & $446 \pm 192$ & ${ }^{* *}$ & $35 \pm 28$ & $28 \pm 22$ & - & $21 \pm 11$ & $64 \pm 42$ & - \\
\hline Thysanoptera & & $13 \pm 8$ & $45 \pm 19$ & - & - & - & - & - & $14 \pm 9$ & - \\
\hline \multirow[t]{2}{*}{ Coleoptera } & Adults & $662 \pm 167$ & $634 \pm 144$ & - & $21 \pm 11$ & $14 \pm 9$ & - & - & $7 \pm 7$ & - \\
\hline & Larvae & $38 \pm 22$ & $89 \pm 22$ & - & $64 \pm 24$ & $134 \pm 70$ & - & $71 \pm 71$ & $35 \pm 19$ & - \\
\hline \multirow[t]{2}{*}{ Diptera } & Adults & $675 \pm 179$ & $1268 \pm 333$ & - & - & - & - & $21 \pm 21$ & $14 \pm 14$ & - \\
\hline & Larvae & $70 \pm 26$ & $159 \pm 59$ & - & $21 \pm 15$ & $21 \pm 11$ & - & - & $21 \pm 15$ & - \\
\hline \multirow[t]{2}{*}{ Hymenoptera } & Adults & $1134 \pm 317$ & $943 \pm 118$ & - & $396 \pm 109$ & $3843 \pm 2920$ & - & $446 \pm 132$ & $1111 \pm 428$ & - \\
\hline & Larvae & $76 \pm 31$ & $140 \pm 34$ & - & - & - & - & - & - & - \\
\hline Lepidoptera & Larvae & $13 \pm 13$ & $7 \pm 7$ & - & - & - & - & $7 \pm 7$ & $14 \pm 9$ & - \\
\hline Others & & $13 \pm 8$ & $25 \pm 14$ & - & - & - & - & - & - & - \\
\hline TOT & & $12429 \pm 3296$ & $25861 \pm 6891$ & - & $7594 \pm 2082$ & $10955 \pm 4624$ & - & $6885 \pm 1540$ & $8273 \pm 2142$ & - \\
\hline
\end{tabular}

$p<0.05$.

${ }^{* *} p<0.01$.

$p<0.001$. 
Table 4

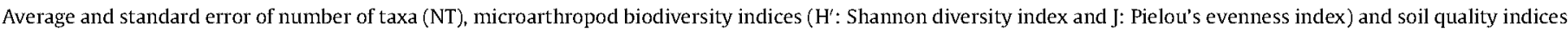

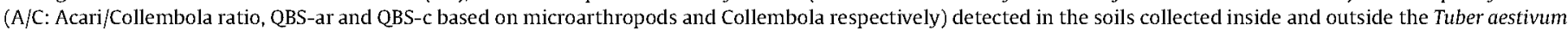
brûlés in the two Italian (areas I and II) and one Spanish (area III) areas; $p$-value: differences between inside and outside of the brûlés.

\begin{tabular}{|c|c|c|c|c|c|c|c|c|c|}
\hline \multirow[b]{2}{*}{ Index } & \multicolumn{3}{|l|}{ Area l } & \multicolumn{3}{|l|}{ Area II } & \multicolumn{3}{|l|}{ Area III } \\
\hline & Inside & Outside & $p$-value & Inside & Outside & $p$-value & Inside & Outside & $p$-value \\
\hline NT & $9 \pm 1$ & $13 \pm 1$ & $* * *$ & $6 \pm 1$ & $8 \pm 1$ & ${ }^{*}$ & $5 \pm 1$ & $7 \pm 1$ & - \\
\hline $\mathrm{H}^{\prime}$ & $1.38 \pm 0.04$ & $1.42 \pm 0.11$ & - & $0.99 \pm 0.80$ & $1.31 \pm 0.12$ & $*$ & $0.73 \pm 0.13$ & $0.89 \pm 0.05$ & - \\
\hline $\mathrm{J}$ & $0.64 \pm 0.04$ & $0.57 \pm 0.05$ & - & $0.57 \pm 0.05$ & $0.63 \pm 0.04$ & - & $0.43 \pm 0.05$ & $0.50 \pm 0.05$ & - \\
\hline $\mathrm{A} / \mathrm{C}$ & $2.11 \pm 0.80$ & $0.93 \pm 0.24$ & - & $1.12 \pm 0.52$ & $1.80 \pm 0.23$ & - & $12.75 \pm 3.36$ & $13.76 \pm 5.21$ & - \\
\hline QBS-ar & $111 \pm 7$ & $164 \pm 10$ & $+* *$ & $83 \pm 10$ & $102 \pm 13$ & 0097 & $76 \pm 8$ & $90 \pm 8$ & - \\
\hline QBS-c & $182 \pm 19$ & $205 \pm 12$ & - & $143 \pm 8$ & $152 \pm 25$ & - & $95 \pm 12$ & $105 \pm 18$ & - \\
\hline
\end{tabular}

${ }^{*} p<0.05$

${ }_{* * *}^{*} p<0.01$.

$p<0.001$.

values outside the burns, and for the Folsomia genus, which displayed the opposite trend.

QBS-ar was the only index that was significantly lower inside the T. aestivum brûlés (Table 4).

\subsubsection{Area II}

We found a density of $7594 \mathrm{ind} / \mathrm{m}^{2}$ inside the brûlés and $10,955 \mathrm{ind} / \mathrm{m}^{2}$ outside (Table 3 ). In this area we found 13 taxonomic groups inside the brûlés and 15 outside, and the number of groups was significantly lower inside than outside (Table 4). Pauropoda abundance was significantly lower inside $T$. aestivum brûlés compared to outside. Acari abundance was lower inside the brûlés, showing relative frequencies ranging from $28 \%$ inside to $33 \%$ outside the brûlés, and Hymenoptera adults showed highly variable relative abundance, ranging from $5 \%$ inside to $35 \%$ outside the brûlés, but the differences were not significant. Coleoptera larvae and Symphyla showed relative abundance higher than $1 \%$, but only outside the brûlés. All the other groups found had relative abundance of less than $1 \%$. Unlike area I, Protura reached high relative abundance in this area, ranging from $2.88 \%$ inside to $4.85 \%$ outside the brûlés, but the differences were not significant. Chilopoda, Hemiptera and Coleoptera adults were not significantly higher inside the $T$. aestivum brûlés compared to outside. Unlike area I, Collembola in this area reached a relative abundance of over $50 \%$ inside and $20 \%$ outside the brûlés (difference not significant). An analysis of the families belonging to the latter group revealed a trend similar to that highlighted in area I (Table 5), although the statistical results have not been confirmed. Almost all families showed higher values associated with samples collected outside the burns, but, in contrast with what we found in area I, the most abundant family, Isotomidae, showed higher values inside the burns. Folsomia genus showed higher densities inside the brûlé, confirming what was observed in area I.

All the indices calculated (Table 4) showed higher values outside the brûlé, but the difference was significant only for the $\mathrm{H}^{\prime}$ index.

\subsubsection{Area III}

We found an average density of $6886 \mathrm{ind} / \mathrm{m}^{2}$ inside the $T$. aestivum brûlés and 8273 ind $/ \mathrm{m}^{2}$ outside. As in area II, Acari was the most representative group, reaching $74 \%$ inside and $71 \%$ outside the T. aestivum brûlés, while Collembola was present with lower relative abundances (10\% inside and 9\% outside). The differences between inside and outside were not significant for either group. As in areas I and II, Hymenoptera was, after Acari and Collembola, the group that reached the highest abundance, $1019 \mathrm{ind} / \mathrm{m}^{2}$ and $3057 \mathrm{ind} / \mathrm{m}^{2}$ inside and outside the brûlé, respectively. Symphyla showed a relative abundance of $1.7 \%$ inside and $2.3 \%$ outside the brûlé, while Coleoptera (larvae) and Lepidoptera (larvae) showed a relative abundance of about $1 \%$ both inside and outside the brûlé. None of the other groups reached $1 \%$. In all cases, the differences were not significant.

The analysis of the Collembola community failed to show any significant differences between the families identified. Nevertheless, some of them revealed the same trends as highlighted in areas I and II. In particular, Isotomidae showed higher values outside the burns, as in area I, while organisms belonging to the Folsomia genus showed higher values inside the burns, as in both the other areas. The indices $\mathrm{H}^{\prime}, \mathrm{J}, \mathrm{A} / \mathrm{C}, \mathrm{QBS}$-ar and QBS-c were higher outside the brûlés, but the differences were not significant (Table 4).

\subsubsection{Differences between areas}

Tukey's test highlights significant differences between the two Italian areas outside the brûlé for Pauropoda ( $p$ : 0.0024), Chilopoda

Table 5

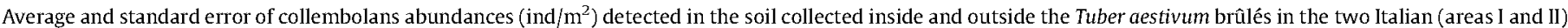
and one Spanish (area III) areas; p-value: differences between inside and outside of the brûlés.

\begin{tabular}{|c|c|c|c|c|c|c|c|c|c|c|}
\hline \multirow[b]{2}{*}{ Families } & \multirow[b]{2}{*}{ Genus } & \multicolumn{3}{|l|}{ Area I } & \multicolumn{3}{|l|}{ Area II } & \multicolumn{3}{|l|}{ Area III } \\
\hline & & Inside & Outside & $p$-value & Inside & Outside & $p$-value & Inside & Outside & $p$-value \\
\hline Entomobryidae & & $217 \pm 93$ & $350 \pm 61$ & - & $120 \pm 31$ & $212 \pm 55$ & - & $85 \pm 28$ & $128 \pm 70$ & - \\
\hline Hypogastruridae & & $170 \pm 109$ & $4787 \pm 3443$ & $* * *$ & $92 \pm 70$ & $170 \pm 74$ & - & $78 \pm 35$ & $78 \pm 31$ & - \\
\hline Isotomidae & & $2325 \pm 940$ & $6212 \pm 1820$ & $* *$ & $2520 \pm 854$ & $863 \pm 144$ & - & $354 \pm 183$ & $439 \pm 201$ & - \\
\hline & Folsomia sp. & $771 \pm 457$ & $19 \pm 14$ & ${ }^{*}$ & $1604 \pm 467$ & $510 \pm 325$ & 0.098 & $64 \pm 24$ & $28 \pm 15$ & - \\
\hline Onychiuridae & & $529 \pm 346$ & $535 \pm 230$ & - & $85 \pm 26$ & $184 \pm 86$ & - & $71 \pm 44$ & $99 \pm 46$ & - \\
\hline Tullbergidae & & $1248 \pm 620$ & $1179 \pm 616$ & - & $7 \pm 7$ & $50 \pm 28$ & - & $43 \pm 28$ & $42 \pm 18$ & - \\
\hline Sminthurididae & & $25 \pm 27$ & $128 \pm 47$ & ${ }^{*}$ & $35 \pm 22$ & $283 \pm 157$ & - & $7 \pm 7$ & - & - \\
\hline TOT & & $5285 \pm 2169$ & $13210 \pm 7015$ & 0.053 & $4465 \pm 1434$ & $2272 \pm 733$ & - & $702 \pm 194$ & $814 \pm 230$ & - \\
\hline
\end{tabular}

${ }_{* *} p<0.05$.

$p<0.001$. 
(p: 0.0027), Protura ( $p: 0.0001)$ and Hemiptera ( $p: 0.026)$. Pseudoscorpiones ( $p: 0.058)$, Chilopoda $(p: 0.053)$ and Collembola ( $p$ : 0.005) showed significant differences between the Italian central area outside the burn and the same Spanish area. Protura showed significant differences between the north Italian area and the Spanish one, both inside and outside the burn ( $p: 0.024$ and $p$ : 0.00004 , respectively), and between the two Italian areas inside ( $p$ : 0.012). Lastly, we found significant differences for Collembola between the north Italian area and the Spanish area inside the burns ( $p$ : 0.005).

\section{Discussion}

This study aimed to highlight the differences in soil fauna between inside and outside the brûlé, as a consequence of the different environment created by T. aestivum. Our results and other studies (García-Montero et al., 2014b) confirmed the ability of $T$. aestivum to modify soil biogeochemistry in the brûlé: $\mathrm{pH}$ was higher and total organic carbon tended to be lower inside the brûlé compared to outside in the three areas investigated. The TOC outcome confirms for T. aestivum the results of previous studies on T. melanosporum brûlés (Callot, 1999; Granetti et al., 2005; GarcíaMontero et al., 2014a; Ricard 2003). The decrease in soil TOC inside both Tuber brûlés can be explained by the ability of both Tuber spp. to minimize the $C$ inputs and turnover, by removing vegetation and other fungus populations from their brûlés (Benucci et al., 2011; García-Montero et al., 2014a; Mello et al., 2011, 2013; Napoli et al., 2010). Gryndler et al. (2013) found that the concentration of $T$. aestivum mycelia in soil is high compared to other ectomycorrhizal fungi, but the concentration of extraradical mycelium in the soil of T. aestivum (Gryndler et al., 2011, 2013) and T. melanosporum (Parladé et al., 2013) brûlés cannot be compared with the soil densely colonised by ECM-mat fungi (covering up to $40 \%$ of the soil surface), showing increased TOC (total organic carbon) and $\mathrm{N}$ values in mat soils compared to non-mat soils (Cromack et al., 1988; Kluber et al., 2010). Therefore, a decrease in soil organic matter content and increase in soil $\mathrm{pH}$ inside $T$. aestivum brûlés, together with other factors associated with the reduction of plant cover (such as variations in soil moisture content, temperature and luminosity), could negatively affect the soil fauna in the brûlés. The findings showed that, like the Collembola families, Hypogastruridae, Sminthurididae and Isotomidae in area I, Symphyla and Pauropoda were more present (in terms of abundance and frequency) outside the T. aestivum brûlé, but this trend was not confirmed in the other two areas. Within the Isotomidae family, Folsomia genus showed higher abundance inside the brûlé in area I and this trend seems to be present in the other two areas. This result suggests that the conditions created by $T$. aestivum inside the brûlé do not have a negative impact on Folsomia genus. This could be due to the group's well-known ability to graze on fungi and hyphae, and $T$. aestivum brûlés could contain a good trophic resource for this genus. A study pointed out that the presence of spores and extraradical mycelium of arbuscular mycorrhizal hyphae was documented (Hodge, 2000) in the gut contents of Folsomia candida. Rotheray et al. (2011) reported that Collembola play a role in determining fungal species combativeness during interactions, with a potential effect on species assemblages and diversity. They reported that the fungal response to Collembolan grazing during interspecific interactions appears to vary according to the combination of grazer species and the identity of the interacting fungi. Hanlon (1981) demonstrated that grazing by Collembola in cultures grown in low-nutrient media produced a significant decline in fungal activity in comparison with controls. Grazing by animals in cultures grown in high-nutrient concentrations did stimulate fungal respiration, however. As suggested by Crowther and A'Bear (2012) in soil microcosm studies, the grazing impact of woodlice (Oniscus asellus), Collembola (Folsomia candida) and millipedes (Blaniulus guttulatus) on the foraging and distribution of two saprotrophic cord-forming basidiomycetes was not only taxon-specific, and within taxa, species-specific but also density-dependent. Larger populations of the three invertebrates limited mycelial development to a greater extent. In another study Gange (2000) showed that some mycorrhizal hyphae are not stimulated to grow at low Collembolan densities, but grazing is detrimental at high densities. At intermediate densities, the preferential removal of small-diameter mycorrhizal hyphae towards the exterior of the mycelium may result in proliferation, and consequently an increase in benefit for the host plant through mineral uptake. In a recent paper, A'Bear et al. (2014) proposed that the increased grazing pressure can counteract, or even amplify, warming-induced stimulation of mycelia growth. In addition, other authors indicate that mites are an important variable in studies of fungal growth during grain drying and storage (Armitage and George, 1986; Sinha and Mills, 1968). It is therefore important to investigate not only grazing pressure due to the Collembola but also the effects of other taxa, which are generally less abundant but play an important role in the soil microflora regulation.

Therefore, our results only partially confirmed the initial hypothesis that $T$. aestivum, by altering soil biogeochemistry and vegetation cover, causes differences in soil microarthropod community, as happens with microarthropod communities in ECM-mat soils (Cromack et al., 1988). We did not in fact observe a univocal trend in the T. aestivum brûlés since some microarthropod groups were less abundant in brûlés and others more abundant. We can suppose that some microarthropod groups, in particular Folsomia genus, may be attracted by the fungal metabolites produced by the mycelium of $T$. aestivum, while others may find an unfavourable environment in the soil of the brûlé. Tuber spp. are symbiotic fungi that depend closely on other organisms to complete their lifecycle. T. aestivum emits volatile organic compounds (VOCs) to attract animal vectors for spore dispersal and possibly other functions (Pacioni et al., 1991; Splivallo et al., 2011). Bellina-Agostinone et al. (1987) found that thiobismethane or dimethyl sulphide is the main VOC compound in T. aestivum. There are strong indications that thiobismethane emissions are recognized by insects and mammals (Culleréa et al., 2010; Díaz, 2002). It is possible that the VOCs play an important role in the microarthropods abundance regulation in the brûlé.

Moreover, our study contributed to highlight differences, in the microarthropod community, not only between inside and outside the brûlés but also comparing the three study areas. Further studies will therefore be required to analyse the biological role play by the different microarthropods, the vegetation phenology (outside the brûlés) and the different climatic conditions in the three study areas.

In conclusion, this study confirmed that the soil in $T$. aestivum brûlés differs partially in terms of $\mathrm{pH}$, TOC, organic matter content and soil microarthropod community, from the soil around it. The three taxa showing differences between these two "environments" were Pauropoda, Symphyla and Hemiptera, suggesting that the conditions in the brûle negatively affected these groups. Among springtails, Hypogastruridae, Isotomidae and Sminthurididae were significantly lower inside the brûlés compared to outside, while Folsomia genus seems to find favourable conditions in the brûlé, in spite of reduced vegetation cover. We hypothesize that Folsomia genus may be attracted by the fungal metabolites produced by $T$. aestivum, and, in relation to their high abundance in the brûlé, could be of interest in Folsomia ecology and T. aestivum ecology and truffle culture. It would be interesting to understand the relationship between Folsomia abundance and T. aestivum fructification and body fruit production and determine whether there is a range of Folsomia abundance within which $T$. aestivum can be 
favoured in its fructification and above which fructification can be depressed, as reported for other fungi with regard to funguscolonised soil.

Lastly, several questions regarding the relationship between soil fauna and T. aestivum brûlé are still open. The next stages of this study would be to determine whether there are fluctuations in terms of presence and abundance of soil microarthropods (especially the less-studied groups, such as Protura and Symphyla) directly or indirectly correlated to the different development and fructification of $T$. aestivum, and extend the research to other truffle species that cause brûlé formation, such as T. melanosporum. Another aspect of interest would be to compare different soil fauna groups, not only arthropods, but also nematodes and earthworms. This would enable us to understand whether Tuber is able to create a natural "microcosm", i.e. the brûlé, as part of a larger macrocosm, the soil around it in terms of soil biodiversity and soil functionality.

\section{References}

A'Bear, A.D., Jones, T.H., Boddy, L., 2014. Potential impacts of climate change on interactions among saprotrophic cord-forming fungal mycelia and grazing soil invertebrates. Fungal Ecol. 10 (1), 34-43.

Anderson, R., 2001. Fungi and beetles. Diversity within diversity. Field Mycol. 2 (3), $82-87$.

Armitage, D.M., George, C.L., 1986. The effect of three species of mites upon funga growth on wheat. Exp. Appl. Acarol. 2, 111-124.

Bachelier, G., 1986. La Vie Animale dans le Sol. ORSTOM, Paris.

Ball, D.F., 1964. Loss-on-ignition as an estimate of organic matter and organic carbon in non-calcareous soils. J. Soil Sci. 15, 84-92.

Bellina-Agostinone, C., Dantonio, M., Pacioni, L.G., 1987. Odor composition of the summer truffle, Tuber aestivum. Trans. Brit. Mycol. Soc. $88,568-569$.

Benucci, G.M.N., Raggi, L., Albertini, E., Grebenc, T, Bencivenga, M., Falcinelli, M., Di Massimo, G., 2011. Ectomycorrhizal communities in a productive Tuber aestivum Vittad. orchard: composition, host influence and species replacement. FEMS Microbiol. Ecol. 76, 170-184.

Blasi, S., Menta, C., Balducci, L., Conti, FD. Petrini, E., Piovesan, G., 2013 Soil microarthropod communities from Mediterranean forest ecosystems in Central Italy under different disturbances. Environ. Monit. Assess. 185 (2), 1637-1655.

Böllmann, J., Elmer, M., Wöllecke, J., Raidl, S., Hüttl, R.F., 2010. Defensive strategies of soil fungi to prevent grazing by Folsomia candida (Collembola). Pedobiologia 53 107-114.

Callot, G., 1999. In: INRA (Ed.), La truffe, La terre, La vie. INRA, Versailles (France)

Callot, G., Daignieres y Fernández, D. Raymond, M., Salducci, X, 1999. Incidences du sol sur la production de truffe noire du Perigord Tuber melanosporum. In: Courvoisier, M., Courvoisier, M., Olivier, J.M., Olivier, J.M., Chevalier, G. Chevalier, G. (Eds.), Proceedings of the Fifth Congres International: Science et Culture de la Truffe, Federation Francaise des Trufficulteurs, Aix-en-Provence. pp. 257-259.

Cromack, K., Fichter, B.L., Moldenke, A.M., Entry, J.A., Ingham, E.R., 1988. Interactions between soil animals and ectomycorrhizal fungal mats. Agric. Ecosyst. Environ. 24, 161-168.

Crowther, T.W., A'Bear, A.D., 2012. Impacts of grazing soil fauna on decomposer fungi are species-specific and density-dependent. Fungal Ecol. 5, 277-281.

Culleréa, L., Ferreira, V., Chevret, B., Venturini, M.E., Sanchez-Gimeno, A.C., Blanco, D., 2010. Characterisation of aroma active compounds in black truffles (Tuber melanosporum) and summer truffles (Tuber aestivum) by gas chromatographyolfactometry. Food Chem. 122, 300-306.

Díaz, P., 2002. Optimizaciín del Aroma de Trufa Tuber Aestivum Mediante Microextracción en Fase Sílida del Espacio de Cabeza (HS-SPME). Msc dissertation, Universidad Autinoma de Madrid, Madrid, Spain.

FAO, 1990. Guideline for Soil Description. FAO, Rome.

Fitter, A.H., Garbaye, J., 1994. Interactions between mycorrhizal fungi and other soi organisms. Plant Soil 159, 123-132.

Fitter, A.H., Sanders, I.R., 1992. Interactions with the soil fauna. In: Allen, M.F., Allen, M.F. (Eds.), Mycorrhizal Functioning, an Integrative Plant-Fungal Process. Chapman \& Hall, London, pp. 333-354.

Gange, A., 2000. Arbuscular mycorrhizal fungi, Collembola and plant growth. TREE $15(9), 369-372$

García-Montero, L.G., Quintana, A., Valverde-Asenjo, I., Díaz, P., 2009. Calcareous amendments in truffle culture: a soil nutrition hypothesis. Soil. Biol. Biochem. 41, 1227-1232.

García-Montero, L.G., Monleon, V., Moreno, D., Valverde-Asenjo, I., Quintana, J. R., de Santiago-Martín, A., Andrês, M.P., 2014a. Vegetation cover and soil characteristics in brûlés of Tuber melanosporum and T. aestivum. Submitted.

García-Montero, L.G., Kuyper, T., Moreno, D., Monleon, V., Myrold, D., Trappe, J. Baham, J., Valverde, I., Parladé, X., Âlvarez, A., Benito, L.F., Quintana, J.R., Parke, J.,
Quintana, A., 2014b. Could ectomycorrhizae perform "ecosystem engineering" on the host plant's rhizosphere? In: Bonet, J.A., Colinas, C., Parladé, X. (Eds.) Proceedings of the Encuentro en Cataluña del proyecto Micosylva. Centre Tecnològic Forestal de Catalunya, Lleida. Submitted.

Gardi, C., Menta, C., Leoni, A., 2008. Evaluation of environmental impact of agricultural management practices using soil microarthropods. Fresen. Environ. Bull. 17 (8b), 1165-1169.

Granetti, B., De Angelis, A., Materozzi, G., 2005. Umbria terra di tartufi. Regione Umbria, Terni.

Gryndler, M., Hrselova, A., Soukupova, L., Streiblova, E., Valda, S., Borovicka, J., Gryndlerova, H., Gazo, J., Milo, M., 2011. Detection of summer truffle (Tuber destivum Vittad.) in ectomycorrhizae and in soil using specific primers. FEMS Microbiol. Lett. 318, 84-91.

Gryndler, M., Trilčová, J., Hršelovâ, H., Streiblová, E., Gryndlerová, H., Jansam, J., 2013. Tuber aestivum Vittad. mycelium quantified: advantages and limitations of a qPCR approach. Mycorrhiza 23, 341-348.

Hanlon, R.D.G., Anderson, J.M., 1979. The effects of Collembola grazing on microbial activity in decomposing leaf litter. Oecologia 38, 93-99.

Hanlon, R.D.G., 1981. Influence of grazing by Collembola on the activity of senescent fungal colonies grown on media of different nutrient concentration. Oikos 36 , 362-367.

Harold, S., Tordoff, G.M., Jones, T.H., Boddy, L., 2005. Mycelial responses of Hypholoma fasciculare to Collembola grazing: effect of inoculums age, nutrient status and resource quality. Mycol. Res. 109, 927-935.

Hodge, A., 2000. Microbial ecology of the arbuscular mycorrhiza. FEMS Microbiol. Ecol. 32, 91-96.

ISRIC, 1995. Procedures for Soil Analysis. FAO, Wageningen, The Netherlands.

Kluber, L.A., Tinnesand, K.M., Caldwell, B.A., Dunhamd, S.M., Yarwood, R.R., Bottomley, P.J., Myrold, D.D., 2010. Ectomycorrhizal mats alter forest soil biogeochemistry. Soil Biol. Biochem. 42, 1607-1613.

Mello, A., Ding, G.C., Piceno, Y.M., Napoli, C., Tom, L.M., De Santis, T.D., Andersen, G.L. Smalla, K., Bonfante, P., 2013. Truffle brûlé have an impact on the diversity of soil bacterial communities. PLoS 8 (4), e61945 doi:http://dx.doi.org/10.1371/ journal.pone.0061945.

Mello, A Napoli, C, Murat, C, Morin, E, Marceddu, G, Bonfante, P, 2011. ITS-1 versus ITS-2 pyrosequencing: a comparison of fungal populations in trufflegrounds. Mycologia 103, 1184-1193.

Menta, C., Leoni, A., Gardi, C., Conti, F.D., 2011. Are grasslands important habitats for soil microarthropod conservation? Biodivers. Conserv. 20, 1073-1087.

Menta, C., Conti, F.D., Pinto, S., Leoni, A., Lozano-Fondón, C., 2014. Monitoring soil restoration in an open-pit mine in northern Italy. Appl. Soil Ecol. (in press).

Napoli, C., Mello, A., Borra, A., Vizzini, A., Sourzat, P., Bonfante, P., 2010. Tuber melanosporum, when dominant, affects fungal dynamics in truffle grounds. New Phytol. 185, 237-247.

Pacioni, G., Bologna, M.A., Laurenzi, M., 1991. Insect attraction by Tuber: a chemical explanation. Mycol. Res. 95 (12), 1359-1363.

Parisi, V., 1974. Soil Biology and Ecology, Techniques of Researches. Boringhieri, Torino (in Italian)

Parisi, V., Menta, C., 2008. Microarthropods of the soil: convergence phenomena and evaluation of soil quality using OBS-ar and OBS-c. Fresen. Environ. Bull. 17 (8), 1170-1174.

Parisi, V., Menta, C., Gardi, C., Jacomini, C., Mozzanica, E., 2005. Microarthropod communities as a tool to assess soil quality and biodiversity: a new approach in Italy. Agric. Ecosyst. Environ. 105, 323-333.

Parladé, J., De la Varga, H., De Miguel, A., Sáez, R., Pera, J., 2013. Quantification of extraradical mycelium of Tuber melanosporum in soils from truffle orchards in northern Spain. Mycorrhiza 23, 99-106.

Plattner, I., Hall, I.R., 1995. Parasitism of non-host plants by the mycorrhizal fungus Tuber melanosporum. Mycol. Res. 99, 1367-1370.

R Core Team, 2013. R: A Language and Environment For Statistical Computing. R Foundation for Statistical Computing, Vienna, Austria. http://www.R-project. org/.

Ricard, J.M., 2003. La Truffe Guide Technique de Trufficulture. Centre Technique Interprofessionnel des Fruits et Légumes CTIFL, Paris.

Rotheray, T.D., Chancellor, M., Jones, T.H., Boddy, L., 2011. Grazing by Collembola affects the outcomer of interspecific mycelia interactions of cord-forming basidiomycetes. Fungal Ecol. 4, 42-55.

Sacchi, C.F., Testard, P., 1971. Ecologie Animale. Doin, Paris.

Sinha, R.N., Mills, J.T., 1968. Feeding and reproduction of the grain mite and the mushroom mite on some species of Penicillium. J. Econ. Entomol. 61, 1548.

Sourzat, P., 2004. Questions d'icologie appliquies à la trufficulture. Lycie Professionnel Agricole de Cahors-Le Montat. Le Montat.

Splivallo, R., Ottonello, S., Mello, A., Karlovsky, P., 2011. Truffle volatiles: from chemical ecology to aroma biosynthesis. New Phytol. 189,688-699.

Tabaglio, V., Gavazzi, C., Menta, C., 2009. Physico-chemical indicators and microarthropod communities as influenced by no-till, conventional tillage and nitrogen fertilization after four years of continuous maize. Soil Till. Res. 105 $135-242$.

Verlhac, A., Giraud, M., Leteinturier, J., 1990. La Truffe Guide Pratique. Centre Technique Interprofessionnel des Fruits et Légumes CTIFL, Paris. 